\title{
SHAPE OPTIMIZATION USING A GENETIC ALGORITHM AND FINITE ELEMENT METHOD
}

\author{
Hermann M.*, Hruš T. .* , Kacálek P.***
}

\begin{abstract}
Our study examines an algorithm for searching ideal shapes of parts according to their functions and lifetime. Due to finite element method (hereinafter referred to as the „FEM“) we obtain maximal equivalent stress at critical part of component or maximum deformation. This is the value of fitness function for genetic algorithm, which is searching for ideal shape of part according to requirements. The goal of the research is to create a universal algorithm that can be used to optimize any component.
\end{abstract}

\section{Keywords: Genetic Algorithm, Optimization of Notch, Mass Distribution on the Beam, Finite Element Method, FreeFem++, Marc-Mentat.}

\section{Introduction}

By the shape optimization is possible to obtain significant decrease of stress or decrease of strain without mass grow, eventually decrease of mass without increasing of stress or decreasing of strain.

General shape optimization is a complex problem with many parameters and huge difficulty. In this paper is presented optimization of a simple construction element - a notch on shaft and mass distribution on the beam.

Notch on shaft works as a stress concentrator. Stress was calculated using FreeFem++, Mentat or Matlab and the shape of the notch was optimized. As optimization criterion was stress concentration used.

Mass distribution on the beam is problem with many parameters. More parameters causes more time to calculate. As optimization criterion can be use maximal deformation in middle of beam or maximal equivalent stress $(\mathrm{HMH})$. The results of optimization for these two criterion are very similar, because stress is dependent on deformation.

\section{Description of the notch geometry}

Notch shape was described by two different ways - as a Bezier curve with three parameters and as a polyline with $\mathrm{n}$ parameters (see Fig. 2). Notch width w and depth d are fixed.

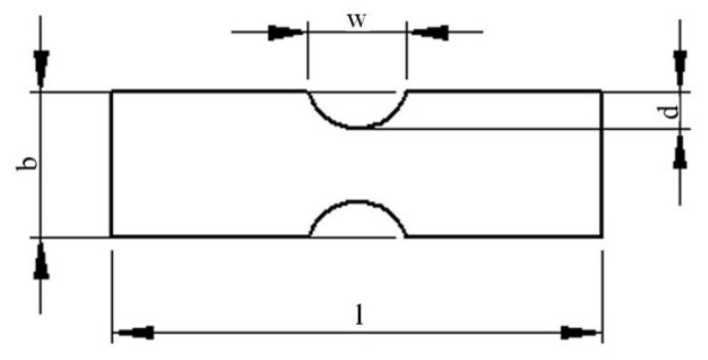

Fig. 1: Shaft dimensions.

\footnotetext{
Hermann Martin: Department of Mechanics; Faculty of Mechanical Engineering; Technical University of Liberec; Studentská 1402/2, 46117 Liberec, Czech Republic, martin.hermann@tul.cz

** Dr. Ing. Tomáš Hruš: Department of Mechanics; Faculty of Mechanical Engineering; Technical University of Liberec; Studentská 1402/2, 46117 Liberec, Czech Republic, tomas.hrus@tul.cz

*** Kacálek Pavel: Department of Mechanics; Faculty of Mechanical Engineering; Technical University of Liberec; Studentská 1402/2, 46117 Liberec, Czech Republic, pavel.kacalek@tul.cz
} 
The first method with only three parameters allows fast optimization, but results may be only inside the class of Bezier curves. The second method allows to describe any shape of notch, but more parameters are necessary.
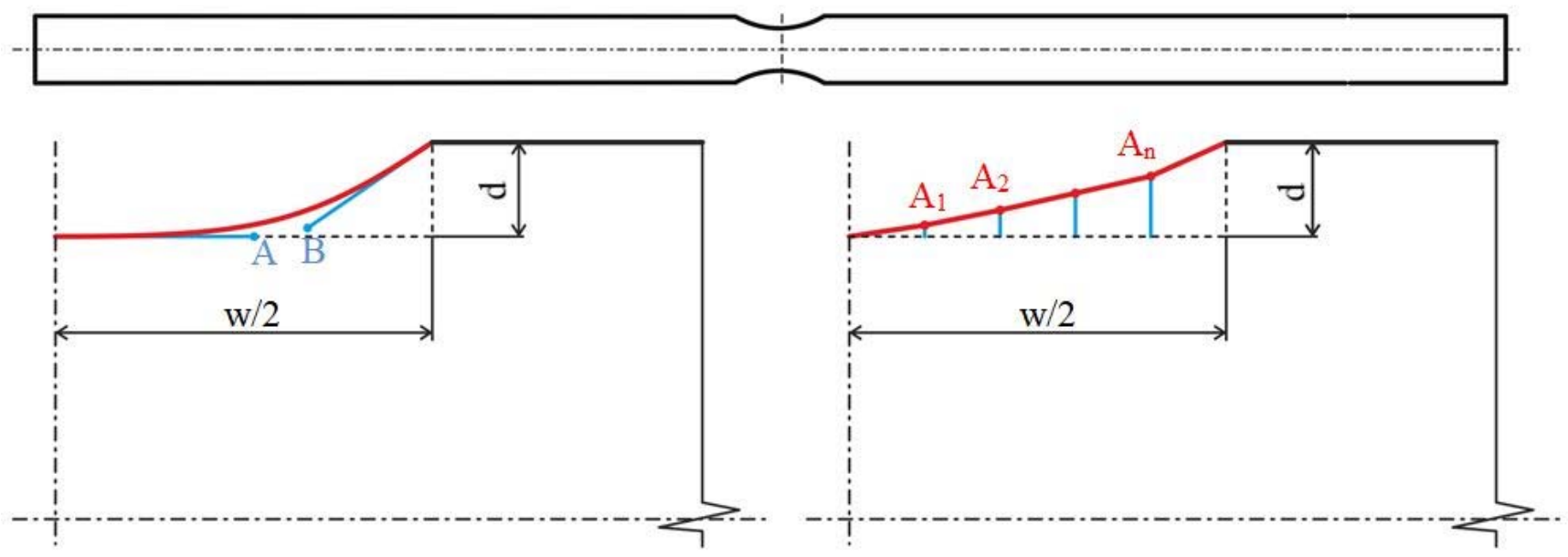

Fig. 2: Top: Bar with a notch, Bottom Left: notch modelled as a Bezier curve and described by $x$-coordinate of point $A$ and $x$ and $y$-coordinates of point $B$.

Bottom Right: notch modelled as polyline described by $y$-coordinates of points $A_{i}$.

\section{Optimized notch shape}

Results for different notch dimensions for bars loaded by tension are in Tab. 1. Optimized notch has lower stress concentrations than reference circular notch.

Tab. 1: Axially loaded bar: stress concentrations for circular and optimized notchs.

\begin{tabular}{|c|c|c|c|}
\hline \multirow{5}{*}{$\begin{array}{l}\text { Circular } \\
\text { Bezier curve } \\
\text { Polyline - } 10 \text { points }\end{array}$} & $\mathrm{d}=5 \mathrm{~mm}$ & $\mathrm{~d}=10 \mathrm{~mm}$ & $\mathrm{~d}=15 \mathrm{~mm}$ \\
\hline & $\mathrm{w}=40 \mathrm{~mm}$ & & \\
\hline & 1.3727 & 1.4780 & 1.4913 \\
\hline & 1.2198 & 1.2972 & 1.2846 \\
\hline & 1.2926 & 1.3561 & 1.2887 \\
\hline \multirow{4}{*}{$\begin{array}{l}\text { Circular } \\
\text { Bezier curve } \\
\text { Polyline - } 10 \text { points }\end{array}$} & $\mathrm{W}=50 \mathrm{~mm}$ & & \\
\hline & 1.2643 & 1.3869 & 1.3653 \\
\hline & 1.1535 & 1.2035 & 1.1863 \\
\hline & 1.2365 & 1.3360 & 1.2115 \\
\hline \multirow{4}{*}{$\begin{array}{l}\text { Circular } \\
\text { Bezier curve } \\
\text { Polyline - } 10 \text { points }\end{array}$} & $\mathrm{w}=60 \mathrm{~mm}$ & & \\
\hline & 1.1943 & 1.2837 & 1.2727 \\
\hline & 1.1110 & 1.1441 & 1.1256 \\
\hline & 1.1656 & 1.2098 & 1.1297 \\
\hline
\end{tabular}
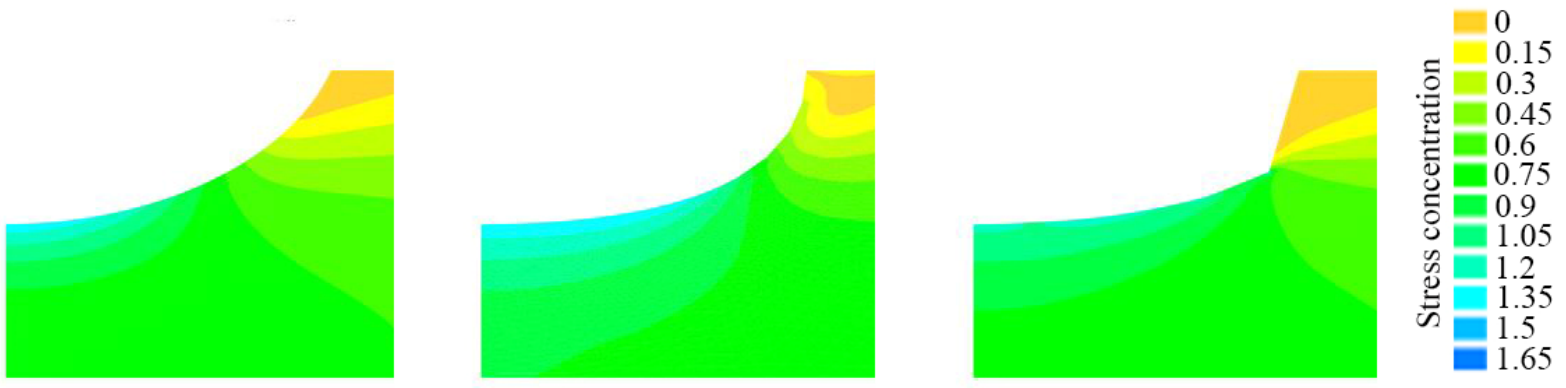

Fig. 2: Axially loaded bar w40d10. Left: Stress concentration in circular notch (Max. $=1.478)$. Center: Stress concentration in notch described by an optimized Bezier curve (Max. $=1.2972)$. Right: Stress concentration in notch described as an optimized polyline with 10 parameters (Max. $=1.3561)$. 


\section{Optimized mass distribution on the beam}

Second example of using genetic algorithm computing in Matlab shows optimized mass distribution on beam fixed on the sides and loaded with force in the middle. The requirement is a constant weight. If the thickness of some element increases, the material must be removed elsewhere to maintain the weight requirement.

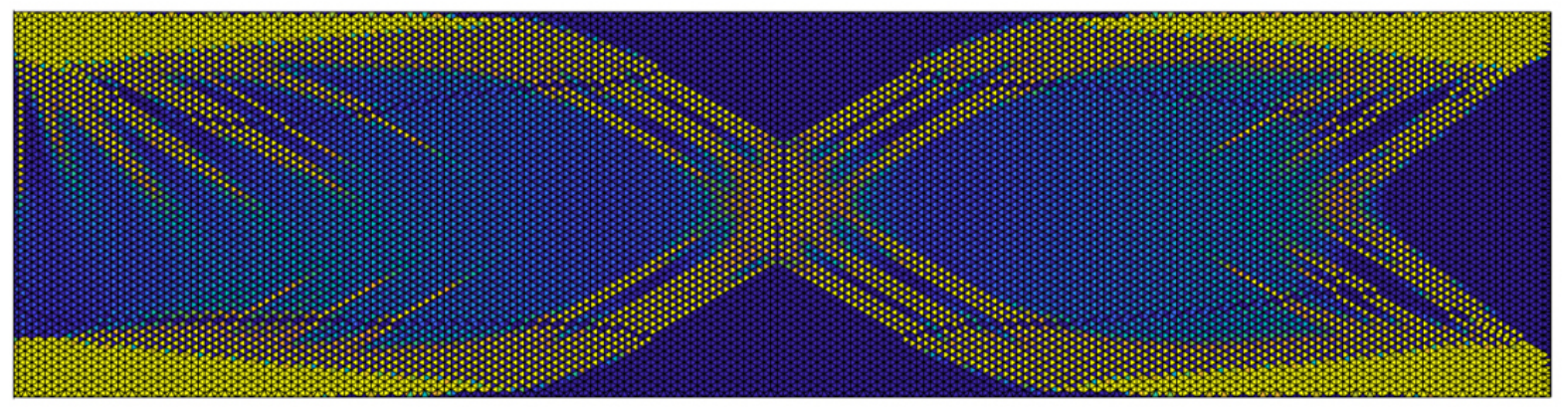

Fig. 3: Optimized mass distribution, beam 1.

In Fig. 4 are thicker elements colored yellow, thinner ones are colored blue. In this case are lot of parameters. Each parameter corresponds to one thickness of element. Number of parameters are equal to number of elements in FEM.

Another loadcase was calculated in FreeFem. Beam on two supports with distributed load along the entire length. In this case is minimizing integral of deflection.

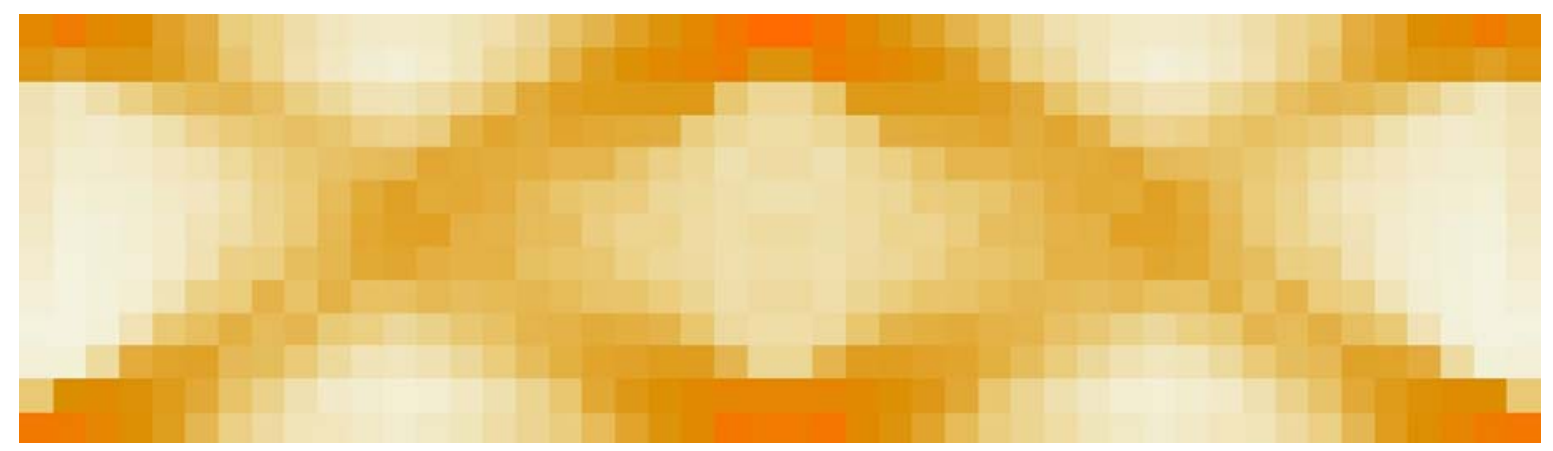

Fig. 4: Optimized mass distribution, beam 2.

\section{Implementation}

FEM was implemented in three ways, as a script in FreeFem++, Matlab and in Marc-Mentat.

Simple scripting language of FreeFem ++ (similar to $\mathrm{C}++$ ) allows fast and effective implementation of required functions.

Genetic algorithm implemented in Matlab with FreeFem++ as external objective function and in FreeFem ++ themselves. Matlab allows more operative modifications of genetic algorithm, FreeFem ++ is faster.

Algorithm for Marc-Mentat is written in Python script and it allows optimized more complex geometry.

\section{Optimization algorithm}

Genetic algorithm was chosen as optimization method, because there is no possibility to explicit derivations formulation of the fitness function. Fitness function is stress concentration (maximal equivalent stress divided by nominal stress) or deformation at a specific location. General behaviour of a fitness function is shown in Fig. 5. 


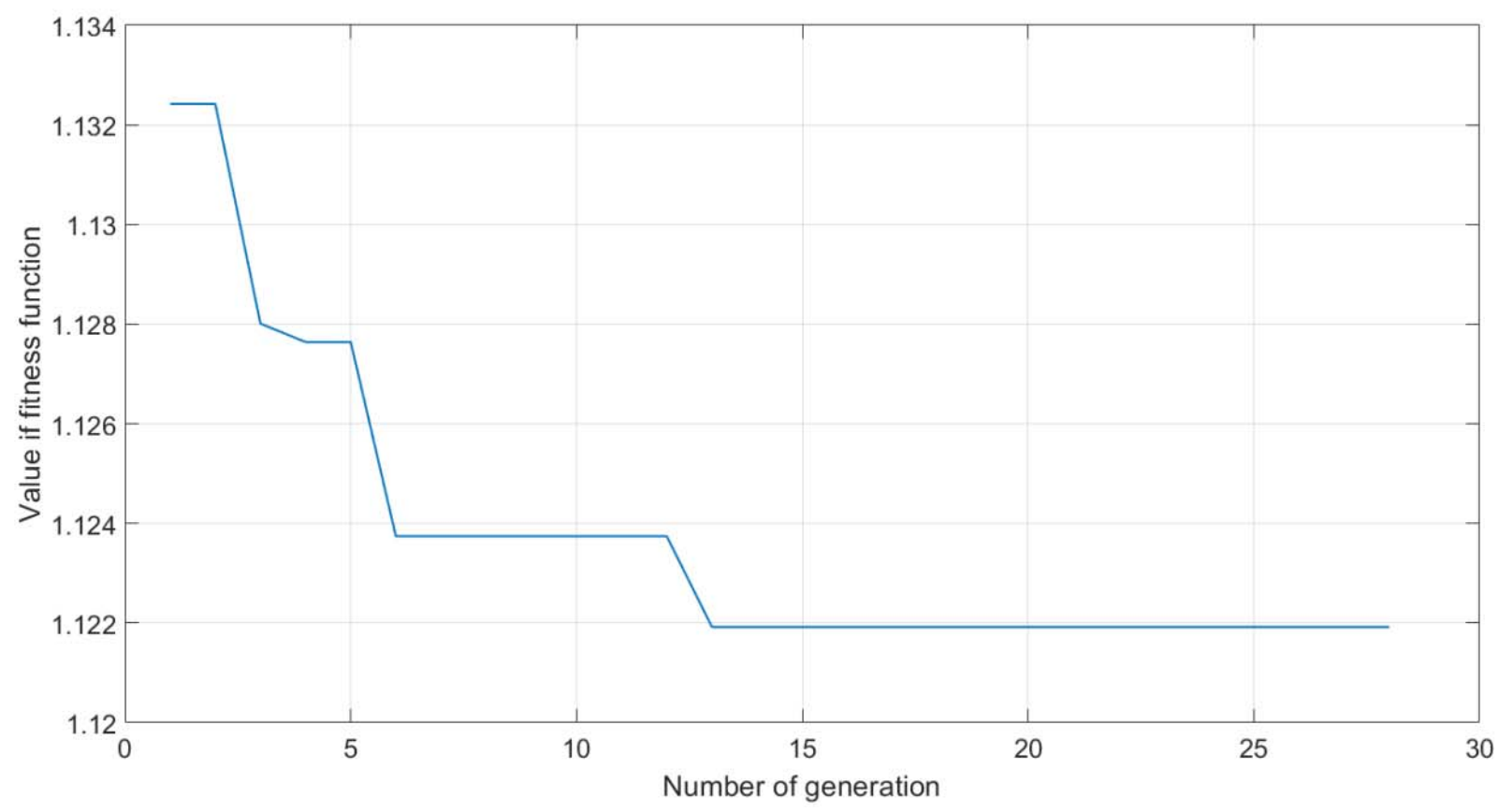

Fig. 5: Behaviour of a fitness function.

\section{Conclusions}

Genetic algorithm is useful and efficient for significant minimization of stress concentration or deformation of component at a specific location. This can be important for lifetime of parts. In this paper is shown just two examples of using algorithm. But once we have a description of part geometry and loadcases, we can optimized shape of any parts.

\section{Acknowledgement}

This work was supported by the Student Grant Competition of the Technical University of Liberec under the project No. SGS-2019-5072.

\section{References}

Hecht, Frédéric. New development in FreeFem++, Journal of numerical mathematics, 2012, vol. 20, no 3-4, pp. 251-266.

Moezi, Seyed Alireza, Zakeri, Ehsan, Bazargan-Lari, Yousef, Zare, Amin. 2d Shape Optimization Via Genetic Algorithm. The Journal of Mathematics and Computer Science (JMCS), 2014. vol. 11, pp. 209-217.

Bassir, D.H., Tang X. G., Zhang, W. H. Material Optimization with Mixed Variables Based on Genetic Algorithm, International Conference on Engineering Optimizations, Rio de Janeiro, Brazil, 2008.

Valackaite, Laisvune, Maciunas, Darius, Glebiene, Elena. Shape Optimization of Two-dimensional Body Utilizing Genetic Algorithms. Conference of Informatics and Management Sciences, 2013, pp. 449-452.

Woon, S.Y., Querin, O.M., Steven, G.P. Structural application of a shape optimization method based on a genetic algorithm. Structural and Multidisciplinary optimization. 2001, vol. 22, pp. 57-64. 